\title{
Genotypic analysis of Mycobacterium tuberculosis from medieval human remains
}

\author{
G. M. Taylor, ${ }^{1}$ M. Goyal, ${ }^{2}$ A. J. Legge, ${ }^{3}$ R. J. Shaw ${ }^{4}$ and D. Young ${ }^{1}$ \\ Author for correspondence: G. M. Taylor. Tel: +44 171594 3946. Fax: +44 1717247349. \\ e-mail: gm.taylor@ic.ac.uk
}

\footnotetext{
1 Department of Infectious Diseases and Microbiology, Imperial College School of Medicine, St Mary's Campus, Norfolk Place, London W2 1PG, UK

2 Department of Biosciences, University of Hertfordshire, Hatfield, Herts AL10 9AB, UK

3 Faculty of Continuing Education, Birkbeck College, 26 Russell Square, London WC1B 5DQ, UK

4 Department of Respiratory Medicine, Imperial College School of Medicine, St Mary's Campus, Norfolk Place, London W2 1PG, UK
}

\begin{abstract}
Three medieval bone samples with osteological evidence of tuberculosis infection were analysed for the presence of DNA sequences from Mycobacterium tuberculosis using a series of PCRs. In each case amplification of IS6110 and part of the $\beta$-subunit of RNA polymerase identified infection with a bacterium belonging to the $M$. tuberculosis complex. Amplification of the mtp40 genome fragment and the presence of a guanine residue at position 285 in the oxyR pseudogene, demonstrated the infecting strain to be similar to present day $M$. tuberculosis isolates rather than to Mycobacterium bovis. Spoligotyping, based on amplification of the direct repeat (DR) region of the mycobacterial genome, provided further evidence of similarity to $M$. tuberculosis and indicated a close relationship between isolates associated with two separate medieval burials. The study demonstrates the feasibility of amplifying multiple $\boldsymbol{M}$. tuberculosis loci in ancient human remains and suggests important applications in the study of the palaeoepidemiology and virulence of tuberculosis in past populations.
\end{abstract}

Keywords: medieval bones, tuberculosis, PCR

\section{INTRODUCTION}

Tuberculosis has plagued mankind throughout recorded history and evidence from skeletal remains attests to its presence in the earliest urbanized societies (Ryan, 1994). Although tuberculosis has declined in most Western countries over the last century, it is estimated that up to one-third of the world's population is currently infected, resulting in 3 million deaths annually (Snider \& La Montagne, 1994). The disease is caused by Mycobacterium tuberculosis, a slow-growing, acid-fast bacterium. M. tuberculosis has microbiological and biochemical characteristics that are almost identical to Mycobacterium bovis, which is responsible for causing disease in cattle and other wildlife species, and which can also infect man (O'Reilly \& Daborn, 1995). Together with other closely related organisms (Mycobacterium microti, Mycobacterium africanum) these bacteria are referred to as the ' $M$. tuberculosis complex'. Spread of infection into man in association with the domestication of animals in early human societies represents a possible mechanism for initiation of the human tuberculosis epidemic. Consistent with this

Abbreviation: DR, direct repeat. model, nucleotide sequence analysis reveals a remarkable absence of allelic variation amongst current isolates of $M$. tuberculosis, suggesting an evolutionary origin within the last 15000 to 20000 years (Sreevatsan et al., 1997).

Analysis of skeletal and mummified remains from tuberculosis patients has demonstrated that fragments of mycobacterial DNA can be preserved over several millennia (Salo et al., 1994; Taylor et al., 1996; Baron et al., 1996; Nerlick et al., 1997). The availability of this material provides the opportunity to test hypotheses concerning the evolution of $M$. tuberculosis using archival samples from different historical periods. In the present study, we have begun to evaluate the potential for this approach by analysing multiple mycobacterial genetic loci in a set of medieval bone samples with osteological evidence of tuberculosis. The bone samples were from the graveyard overlying part of the Black Death cemetery on the site of the old Royal Mint in London. The cemetery was associated with the Abbey of St Mary Graces, the last Cistercian foundation in England, which was founded in 1350 and lasted until the dissolution in 1538 . We have previously reported amplification of a characteristic M. tuberculosis DNA fragment (IS6110) from these specimens (Taylor et al., 1996). 
While conventional microbiological techniques distinguish $M$. tuberculosis from $M$. bovis, a rapidly expanding series of genomic tools allows a much more incisive discrimination amongst members of the $M$. tuberculosis complex. For the most part, genes encoding functionally important enzymes show almost no sequence variation, except in cases where changes are selected by their ability to confer drug resistance (Sreevatsan et al., 1997). However, single base pair variations identified in genes encoding catalase ( $k a t G$ ) and gyrase $(g y r A)$ have been used to categorize $M$. tuberculosis isolates into three broad groups (Sreevatsan et al., 1997) and a variation in the pyrazinamidase gene ( $n n c A)$ distinguishes bovine from human isolates (Espinosa de los Monteros et al., 1998). Interestingly, the $p n c A$ sequence of $M$. bovis isolates from goats resembles that of human $M$. tuberculosis rather than that generally associated with M. bovis (Espinosa de los Monteros et al., 1998). The gene encoding the OxyR oxidative response regulator has been disrupted to form a pseudogene in $M$. tuberculosis and again a sequence polymorphism distinguishes $M$. bovis from $M$. tuberculosis (Sreevatsan et al., 1996). Analysis of repetitive DNA sequences and mobile insertion elements reveals much more extensive heterogeneity amongst $M$. $t u$ berculosis isolates. The chromosomal distribution of copies of IS6110 forms the basis of a widely used fingerprint analysis for discriminating $M$. tuberculosis isolates (Cohn \& O'Brien, 1998) and the pattern of unique variable sequences interspersed within a conserved direct repeat (DR) region has been exploited in a technique known as 'spoligotyping' (Kamerbeek et al., 1997). Spoligotyping provides an approach for distinction of broad groups of M. bovis and M. tuberculosis and again highlights a closer relationship between human and caprine as compared to bovine isolates (Aranaz et al., 1996; Gutierrez et al., 1997). Finally, analysis of a region including a phospholipase $\mathrm{C}$ gene in M. tuberculosis - a sequence referred to as mtp 40 - has resulted in the design of amplification assays allowing distinction of M. tuberculosis from most (but not all) $M$. bovis isolates (Del Portillo et al., 1991; Weil et al., 1996; Liebana et al., 1996).

With the recent publication of the complete genome of M. tuberculosis $\mathrm{H}_{37} \mathrm{Rv}$ (Cole et al., 1998) and the anticipation of additional M. tuberculosis and M. bovis genome sequences, we wished to exploit these genomic tools for analysis of historical isolates. In this study we report amplification of five different genetic loci from bone samples from tuberculosis victims and demonstrate that bacteria responsible for the medieval infection were more closely related to present day $M$. tuberculosis than to M. bovis.

\section{METHODS}

Bone samples and DNA extraction. Three bone specimens from two separate burials were obtained from the cemetery associated with the Abbey of St Mary Graces (1350-1538) on the site of the old Royal Mint in London. Each of the samples had osteological evidence of tuberculosis. An extract from a lumbar vertebra from the same burial site but with no osteological evidence of tuberculosis was included as a negative control. The bones have been described in detail by Taylor et al. (1996). DNA was extracted from bone powder (100-200 mg) using the Nuclisens guanidinium/silica kit from Organon Teknika.

PCR methods. With the exception of spoligotyping, which was performed exactly as described below, a number of PCR steps were common to all methods. Each PCR reaction mixture consisted of $25 \mathrm{pmol}$ each primer in $1 \mu \mathrm{l}, 2.5 \mu \mathrm{l} 10 \times$ reaction buffer (Promega), $200 \mu \mathrm{mol}$ each deoxyribonucleotide (Pharmacia), in a total volume of $2.5 \mu \mathrm{l}, 2-5$ units Taq DNA polymerase (Promega) and $1.5-3 \mu 15 \mathrm{mM} \mathrm{MgCl}_{2}$. Bone extract or template was added in a volume of $5 \mu \mathrm{l}$ and the sample was then made up to $25 \mu \mathrm{l}$ with HPLC grade water (Merck). Template blanks, with water in place of sample, were always included. The reaction was overlaid with 1 drop of mineral oil to prevent evaporation. The optimum magnesium concentration and annealing temperatures were determined for each primer pair in preliminary experiments. All methods included an initial denaturation step at $94{ }^{\circ} \mathrm{C}$ for 3 min before a 'hotstart' with addition of Taq DNA polymerase at $85^{\circ} \mathrm{C}$. Reaction tubes were held at $4{ }^{\circ} \mathrm{C}$ after the run.

PCR amplification was performed using either a Hybaid Touchdown subambient thermal cycler with both 0.5 and $0.2 \mathrm{ml}$ blocks or a Hybaid Sprint cycler. Annealing temperatures were optimized on a RoboCycler (Stratagene).

Various precautions were taken to avoid contamination with modern DNA. These have been described previously (Taylor et al., 1996, 1997). A lumbar vertebra taken from the same site but with no osteological evidence of tuberculosis was used as a negative control.

156110. A 'hot-start' nested PCR for the IS6110 insertion element was performed as described previously (Taylor et al., 1996). This is a modification of the method described by Thierry et al. (1990).

RNA polymerase $(r p o B)$. Amplification of the $\beta$-subunit of the RNA polymerase gene (rpoB) of the M. tuberculosis complex was performed using the INNO-LiPA Rif.TB Kit (Innogenetics). This kit is a line hybridization assay which specifically detects rifampicin resistance after amplification of the relevant region of the $r p o B$ gene of $M$. tuberculosis complex (De Beenhouwer et al., 1995). Biotinylated primers for sensitive nested PCR are supplied with the kit. Amplified PCR products ( $411 \mathrm{bp}$ from first round or $257 \mathrm{bp}$ from nested PCR) were hybridized with specific oligonucleotide probes (corresponding to wild-type or resistant mutant alleles) immobilized as parallel lines on membrane-based strips. In addition to organisms of the $M$. tuberculosis complex, the primers will also amplify various other mycobacterial species and confirmation of $M$. tuberculosis is provided by a further specific probe on the strips. In this study the kit was used as described in the manufacturer's instructions and a modified procedure was evaluated for older specimens likely to contain more degraded DNA. The kit inner primers were used in a first round of amplification followed by nested PCR with a second pair of biotinylated primers [5' TGCACGTCGCGGACCTCCA 3' (forward) and 5' TCGCCGCGATCAAGGAGTTC $3^{\prime}$ (reverse)] (Telenti et al., 1993) to generate a 157 bp product. The cycling parameters for $r p o B$ PCR were as described in the kit. For the Telenti primers, the cycle consisted of 35 cycles of $94{ }^{\circ} \mathrm{C}$ for $30 \mathrm{~s}$ and $66^{\circ} \mathrm{C}$ for $30 \mathrm{~s}$ with a final cycle at $72{ }^{\circ} \mathrm{C}$ for $2 \mathrm{~min}$.

mtp40. Primers 5' CTGGTCGAATTCGGTGGAGT 3' (for- 
ward) and 5' ATGGTCTCCGACACGTTCGAC 3' (reverse) were used. The primers amplified a $152 \mathrm{bp}$ product. The cycling parameters were 45 cycles of $94^{\circ} \mathrm{C}$ for $30 \mathrm{~s}$ and $66^{\circ} \mathrm{C}$ for $45 \mathrm{~s}$ with a final cycle at $72{ }^{\circ} \mathrm{C}$ for $1 \mathrm{~min}$. The optimum magnesium concentration was $2 \mathrm{mM}$.

$M$. bovis-specific fragment. PCR for an $M$. bovis-specific fragment was performed using primers JB21 and JB22 as described by Rodriguez et al. (1995). Cycling parameters were modified to 45 cycles of $94{ }^{\circ} \mathrm{C}$ for $25 \mathrm{~s}, 62^{\circ} \mathrm{C}$ for $30 \mathrm{~s}$ and $72{ }^{\circ} \mathrm{C}$ for $30 \mathrm{~s}$. The optimum magnesium concentration was $2 \mathrm{mM}$.

oxy $R$ pseudogene. Primers were designed to amplify a $150 \mathrm{bp}$ fragment from the oxyR pseudogene of $M$. tuberculosis $\mathrm{H}_{37} \mathrm{Rv}$ strain (accession no U16243). The sequence of the primers was 5' CGCGCTGTCAGAGCTGACTTT 3' (forward) and 5' TCTGCGGAATCAGTGTCACC 3' (reverse). Forty-five cycles of amplification were performed. The stages were $94^{\circ} \mathrm{C}$ for $10 \mathrm{~s}, 62^{\circ} \mathrm{C}$ for $30 \mathrm{~s}$ and $72{ }^{\circ} \mathrm{C}$ for $15 \mathrm{~s}$. A final elongation cycle was performed at $72{ }^{\circ} \mathrm{C}$ for $2 \mathrm{~min}$.

Spoligotyping. Spoligotyping (spacer-oligonucleotide typing) was performed as described by Kamerbeek et al. (1997) with the minor modification of an increase in cycle number up to 45 cycles. The amplified products were hybridized to a set of 43 oligonucleotides immobilized on a Biodyne- $\mathrm{C}$ transfer membrane (Pall Europe). Each oligonucleotide sequence corresponded to one of the unique spacer DNA sequences within the DR locus. Detection of hybridizing DNA was achieved by incubation with streptavidin-horseradish peroxidase (HRP) conjugate followed by chemiluminescent ECL detection liquid (Amersham) and then by exposure to X-ray film (Hyperfilm ECL; Amersham).

Automated DNA sequencing. Cycle sequencing of PCR products was performed on the Hybaid Touchdown with the ABI Dye Terminator Ready Reaction kit (Perkin Elmer/ Applied Biosystems), according to the manufacturer's protocol, with subsequent analysis on an ABI 310 Genetic Analyser.

Gel electrophoresis. Routine gel electrophoretic analysis of products was performed on $3 \%(\mathrm{w} / \mathrm{v})$ agarose gels as described previously (Taylor et al., 1996). Products for sequencing were subsequently run on $0.8 \%$ LMP agarose (Gibco-BRL). Bands were excised from the gel with a sterile scalpel blade and purified using the NucleiClean DNA isolation kit (Sigma/Aldrich).

\section{RESULTS}

\section{Evidence of tuberculosis infection}

Three medieval bone specimens were analysed for the presence of $M$. tuberculosis DNA. A fused wrist sample (W 1) came from the skeleton of a male in his middle years at the time of death. Two adjacent lumbar vertebrae (LV 1 and LV 2) came from the skeleton of a male aged between 15 and 25 years at death. In the case of the first individual, there was evidence of healing with minimal reactive bone formation. In the younger male, large cavitating lytic lesions, indicative of past abscess formation, were present in both vertebrae. These bone samples have previously been described in greater detail (Taylor et al., 1996). For each sample, bone was powdered and a DNA extract was prepared and amplified using nested PCR with primers specific for

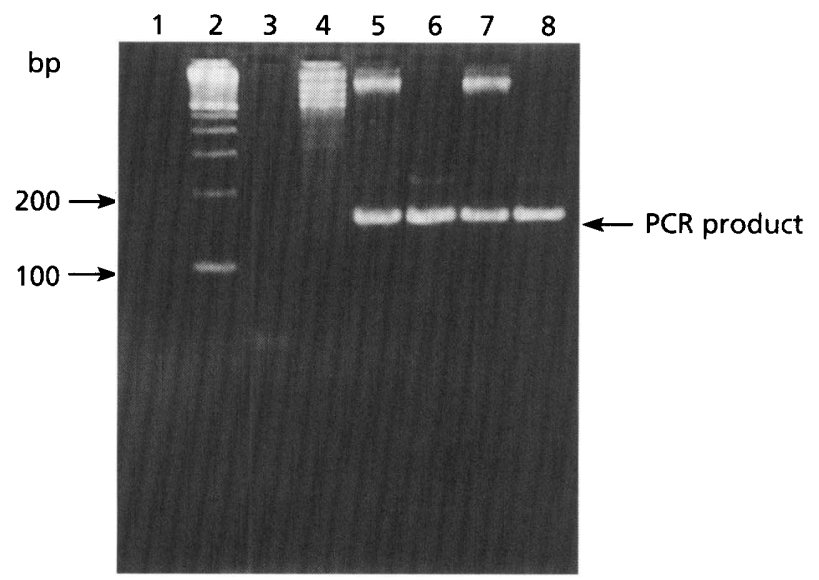

Fig. 1. $P C R$ amplification of the $r p o B$ gene. Samples were tested for the presence of $r p O B$ by PCR amplification of a $157 \mathrm{bp}$ fragment. Products were analysed by electrophoresis in a $3 \%(w / v)$ agarose gel and visualization by ethidium bromide. Lanes: 1, no sample; 2, 100 bp DNA size markers; 3, second round template blank; 4, first round template blank; $5, M$. tuberculosis $\mathrm{H}_{37} \mathrm{Rv}$ positive control; 6 , lumbar vertebral extract (LV 1); 7, lumbar vertebral extract (LV 2); 8, wrist extract (W 1).

IS6110. Consistent with previous results (Taylor et al., 1996), all new extracts prepared for the present study each generated a clear IS6110 PCR signal, confirming tuberculosis infection. The same extracts were then used to study additional mycobacterial loci.

\section{RNA polymerase gene (rpoB)}

The gene encoding the $\beta$-subunit of RNA polymerase is altered in most rifampicin-resistant isolates of $M$. tuberculosis and this gene has been used extensively as a target for PCR amplification (De Beenhouwer et al., 1995; Telenti et al., 1993; Goyal et al., 1997). The medieval bone extracts were tested for the $r p o B$ gene using two nested PCR protocols designed to generate 257 and 157 bp products, respectively. In each case, a PCR product of the expected size was obtained; Fig. 1 (lanes 6-8) demonstrates the presence of the $157 \mathrm{bp}$ signal. The PCR products were further analysed using the INNO-LiPA kit for detection of rifampicin-resistant alleles (De Beenhouwer et al., 1995). The test involves assay for hybridization to a series of oligonucleotide sequences corresponding to wild-type or resistant alleles. PCR products from the medieval samples all showed a pattern of specific hybridization to the wildtype sequences, consistent with the anticipated infection with a fully drug-sensitive member of the $M$. tuberculosis complex.

\section{mtp40 and $M$. bovis-specific PCR}

DNA extracts were subjected to PCR amplification using primers for mtp40, a region found in most $M$. tuberculosis isolates (Del Portillo et al., 1991) and for a 


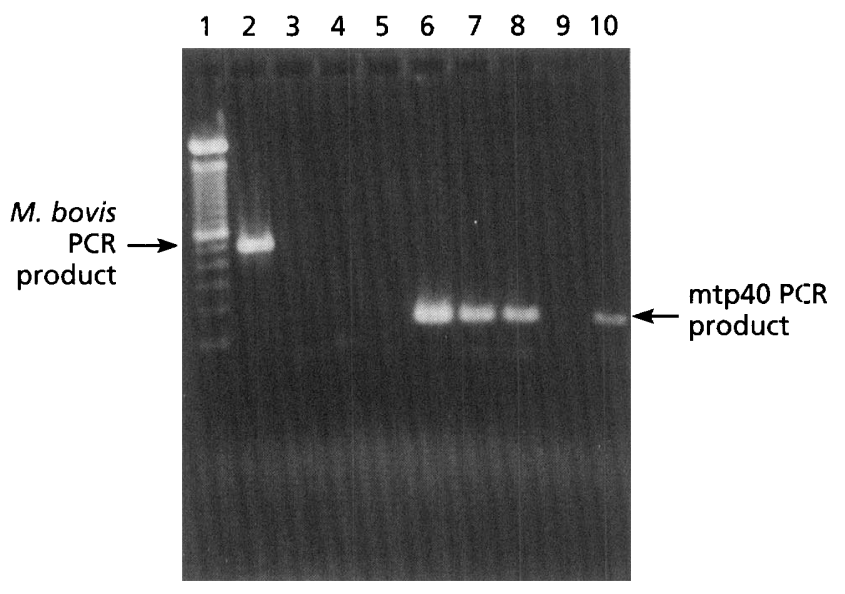

Fig. 2. $P C R$ amplification of $m \operatorname{mtp} 40$ and an $M$. bovis-specific DNA fragment. Samples were tested for the presence of an $M$. bovis-specific DNA fragment (lanes $2-5$ ) and $M$. tuberculosisspecific mtp40 (lanes 6-10) by PCR amplification. Products were analysed by electrophoresis in a $3 \%(w / v)$ agarose gel and visualization by ethidium bromide. Lane 1, 100 bp DNA size markers. Lanes: $2, M$. bovis BCG positive control; 3, extraction blank; 4, wrist extract (W 1); 5 , lumbar vertebral extract (LV 1). Lanes: 6, $M$. tuberculosis $\mathrm{H}_{37} \mathrm{Rv}$ positive control (mtp40); $7, \mathrm{~W} 1$ with $4 \cup$ Taq; 8, LV 1 with 4 U Taq; 9, W 1 with $2 \cup$ Taq; 10, I-V 1 with $2 \cup$ Taq.

DNA fragment previously identified as specific to $M$. bovis (Rodriguez et al., 1995). The anticipated 152 bp mtp40 product was obtained from the lumbar samples and from the wrist sample, though in the latter case additional $\mathrm{Taq}$ polymerase was required for a positive reaction. The results are illustrated in Fig. 2. Cycle sequencing confirmed $100 \%$ identity with the expected products. No product was obtained from any of the samples using the M. bovis-specific primer set.

\section{oxyR pseudogene}

A PCR reaction designed to amplify a $150 \mathrm{bp}$ fragment from the oxyR pseudogene generated a product only with lumbar sample LV 2. Automated sequencing of both strands of the PCR product showed the presence of a guanine residue at position 285 , characteristic of $M$. tuberculosis, rather than the adenine found in present day M. bovis (Sreevatsan et al., 1996).

\section{Spoligotyping}

Primers specific for the DR region were used to amplify DNA fragments from each of the three bone samples and the resulting PCR products were tested for hybridization to a set of oligonucleotides corresponding to variable intervening sequences. The three samples showed similar hybridization patterns (Fig. 3). The five $3^{\prime}$ end spacers (on the right in Fig. 3) are generally absent from M. bovis isolates (Kamerbeek et al., 1997) and positive signals for at least four of these suggest that the bone samples are more closely related to $M$. tuberculosis than to M. bovis. It would be anticipated that LV 1 and LV 2, from a single individual, would correspond to an identical isolate and it is not clear whether minor differences apparent in the spoligotype profile represent a genuine difference or an incomplete amplification of the whole DR region in the two samples. Similarly, the spoligotype of the wrist sample resembles that of the lumbar samples, but further analysis would be required to establish whether a single isolate was responsible for both cases.

\section{Reproducibility of results}

Three extracts were prepared from both wrist and lumbar vertebral specimens. IS6110 PCR was performed once on each and was always positive. PCR for the $r p o B$ subunit followed by INNO-LiPA testing was performed on two of the extracts on two separate occasions with identical results. PCR for mtp40 was positive in two extracts from each sample and M. bovis PCR, performed simultaneously, was always negative. Spoligotyping was reproducible in two extracts from each bone but was unsuccessful in the third extract. $0 x y R$ PCR was performed once upon a single extract from each case but only amplified from the younger male with vertebral tuberculosis. Figs 1-3 illustrate representative results.

\section{DISCUSSION}

PCR amplification of mycobacterial DNA sequences in historic samples has usually been undertaken to confirm diagnosis of infectious diseases such as leprosy (Rafi et al., 1994) or tuberculosis (Salo et al., 1994; Taylor et al., 1996; Baron et al., 1996) which leave clear osteological evidence on human skeletal remains or, less frequently, which may persist in other mummified tissues (Nerlick

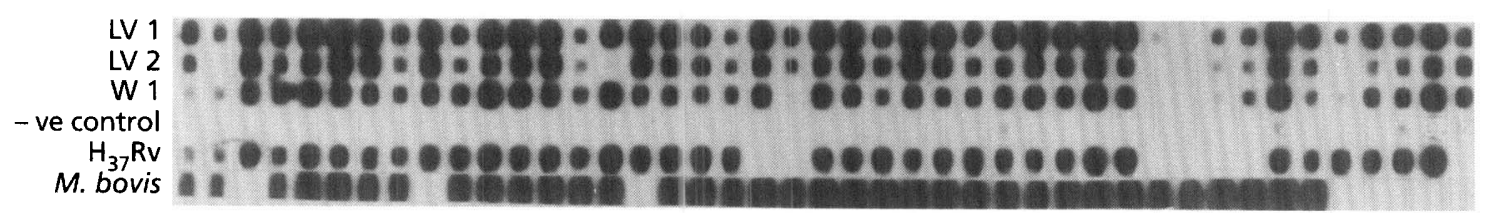

Fig. 3. Spoligotype analysis of samples from medieval bones. DNA extracted from bone samples was amplified using primers specific for the DR region and PCR products were tested for hybridization to unique spacer sequences. The top three rows show hybridization patterns generated using extracts from lumbar vertebrae and wrist extracts. Row 4 is a negative control generated using a similar DNA extract prepared from a contemporary lumbar vertebra from the same burial site with no osteological evidence of tuberculosis. Rows 5 and 6 show patterns obtained with $M$ tuberculosis $H_{37} R v$ and with $M$. bovis BCG, respectively. 
Table 1. Summary of bone samples and results of genotypic analysis

\begin{tabular}{|c|c|c|c|c|c|c|c|}
\hline \multirow[t]{2}{*}{ Bone sample } & \multirow{2}{*}{$\begin{array}{c}\text { Osteological } \\
\text { evidence of TB }\end{array}$} & \multicolumn{6}{|c|}{ PCR amplification product } \\
\hline & & IS 6110 & $r p o B$ & $\begin{array}{l}\text { mtp40 } \\
\text { fragment }\end{array}$ & M. bovis & $\operatorname{oxy} R$ & $\begin{array}{c}\text { DR region } \\
\text { (spoligotype) }\end{array}$ \\
\hline Lumbar vertebra (LV 1) (male 15-25 years) & Yes & + & + & + & - & - & + \\
\hline Lumbar vertebra (LV 2) (male $15-25$ years) & Yes & + & + & + & - & $\begin{array}{c}+ \\
(\mathrm{G} \text { at 285) }\end{array}$ & + \\
\hline Lumbar vertebra (control) & No & - & - & - & ND & ND & - \\
\hline
\end{tabular}

ND, Not determined.

et al., 1997). Tuberculosis has been most studied as the pathological indications on bone are quite distinctive, although only a relatively small percentage of cases of tuberculosis actually result in skeletal pathology. Most studies have used a single genetic locus, IS6110 being the marker of choice due to the inherent sensitivity offered by PCR amplification of a multiple-copy element within the tuberculosis genome (Salo et al., 1994; Taylor et al., 1996; Baron et al., 1996). Recently, there was a report which indicated that IS6110 may be present in other species of mycobacteria (Kent et al., 1995). A recent reevaluation of IS6110 has confirmed that the regions initially chosen for amplification are specific for the $M$. tuberculosis complex (Hellyer et al., 1996). However, part of the sequence may share homology with insertion sequences present in other species and care must be taken when designing new PCR methods based on IS6110 amplification (Hellyer et al., 1996).

We wished to evaluate the potential of microbial palaeogenetics, which we would define as the study of mycobacterial genotypes associated with disease in ancient remains, not simply as a confirmatory tool for diagnosis, but as an approach to study the evolutionary biology of M. tuberculosis.

The factors that determine preservation of microbial DNA in bone samples are not well understood, although current evidence suggests that this is generally in the form of short fragments rather than as intact chromosomes (Kelman \& Moran, 1996). Some sequences may be more susceptible to degradation than others as a consequence of the physical assembly of the chromosome or interaction with other macromolecules. It was of interest that, of the five M. tuberculosis sequences tested in this study, we obtained amplification products for each one in at least one extract (Table 1). Experience with other bone samples suggests that this is not always the case, with some primers (for example, the oxyR pseudogene) often failing to generate products. Failure to obtain a positive signal for a particular locus does not provide definitive evidence of its absence from the original genome. Nested PCR protocols, such as those used for IS6110 and rpoB, clearly have advantages in terms of sensitivity. In spite of the problem associated with failure to preserve individual loci, it is likely that the growing body of information generated by comparative mycobacterial genomics will identify a broad array of variable loci for use in future palaeogenetic studies.

In addition to confirmation of the original diagnosis of tuberculosis in the Royal Mint medieval bones, this study has generated further information about the infecting organisms. Analysis of the $r p o B$ gene confirms the infection to be due to an organism belonging to the M. tuberculosis complex and excludes the possibility of a drug-resistant strain. The positive mtp40 amplification signals, together with the $o x y R$ sequence data, are consistent with infection due to an organism more closely resembling present day M. tuberculosis than $M$. bovis. Similarly, the profile revealed by spoligotyping indicates a closer relationship to $M$. tuberculosis. The PCR format of spoligotyping represents a significant advantage over IS6110 fingerprinting for this type of examination and the positive results obtained suggest the possibility of carrying out epidemiological analysis upon transmission of tuberculosis with samples excavated from archaeological sites. It is important to bear in mind, however, that the DR region may not remain intact in all samples and that minor differences in spoligotype could reflect differences in the preservation of the DR region rather than genuine differences in genotype.

An extension of the approach we have taken in this study - using a wider range of genetic markers in bone samples from different historical sites-potentially represents a powerful new approach to understand the development of the M. tuberculosis complex. Based on analysis of current isolates, Sreevatsan et al. (1997) have proposed a phylogeny based on initial divergence between $M$. bovis and group 1 strains of $M$. tuberculosis, with subsequent evolution of group 2 and group 3 organisms. Other studies have pointed out a relationship between $M$. tuberculosis and caprine strains of M. bovis that suggest transmission from domestication of goats, rather than cattle, as a possible origin of the human disease (Espinosa de los Monteros et al., 1998; Aranaz et al., 1996; Gutierrez et al., 1997). This would accord with current evidence from Southwest Asia for the prior domestication of caprines (Legge, 1996). The ability to 
obtain detailed genetic information on archaeological samples will assist in rigorous assessment of these hypotheses.

\section{ACKNOWLEDGEMENTS}

DNA prepared from $M$. bovis BCG was kindly supplied by Dr Koen De Smet, Action TB Laboratory, Department of Infectious Diseases and Microbiology, Imperial College School of Medicine, London. This work was supported in part: by a grant from Birkbeck College, University of London.

\section{REFERENCES}

Aranaz, A., Liebana, E., Mateos, A. \& 8 other authors (1996). Spacer oligonucleotide typing of Mycobacterium bovis strains from cattle and other animals: a tool for studying epidemiology of tuberculosis. J Clin Microbiol 34, 2734-2740.

Baron, H., Hummel, S. \& Herrmann, B. (1996). Mycobacterium tuberculosis complex DNA in ancient human bones. $J$ Archaeol Sci 23, 667-671.

Cohn, D. L. \& O'Brien, R. J. (1998). The use of restriction fragment length polymorphism (RFLP) analysis for epidemiological studies of tuberculosis in developing countries. Int J Tuberc Lung Dis?, 16-26.

Cole, S. T., Brosch, R., Parkhill, J. \& 39 other authors (1998). Deciphering the biology of Mycobacterium tuberculosis from the complete genome sequence. Nature 393, 537-544.

De Beenhouwer, H., Lhiang, Z., Jannes, G., Mijs, W., Machtelinckx, L., Rossau, R., Traore, H. \& Portaels, F. (1995). Rapid detection of rifampicin resistance in sputum and biopsy specimens from tuberculosis patients by PCR and line probe assay. Tubercle Lung Dis 76, 425-430.

Del Portillo, P., Murillo, L. A. \& Patarroyo, M. E. (1991). Amplification of a species-specific DNA fragment of Mycobacterium tuberculosis and its possible use in diagnosis. J Clin Microbiol 29, 2163-2168.

Espinosa de los Monteros, L. E., Galan, J. C., Gutierrez, M. \&: 8 other authors (1998). Allele-specific PCR method based on pn:A and $o x y R$ sequences for distinguishing Mycobacterium bovis from Mycobacterium tuberculosis: intraspecific $M$. bovis pncA polymorphism. J Clin Microbiol 36, 239-242.

Goyal, M., Shaw, R. J., Banerjee, D. K., Coker, R. J., Robertson, B. D. \& Young, D. B. (1997). Rapid detection of nosocomial spread of multi-drug resistant tuberculosis. Eur Respir J 10, 1120-1124.

Gutierrez, M., Samper, S., Jimenez, M. S., van Embden, J., Marin, J. F. G. \& Martin, C. (1997). Identification by spoligotyping of a caprine genotype in Mycobacterium bovis strains causing human tuberculosis. J Clin Microbiol 35, 3328-3330.

Hellyer, T., DesJardin, L. E., Assaf, M. K., Bates, J. H., Cave, M. D. \& Eisenach, K. D. (1996). Specificity of IS6110-based amplification assays for Mycobacterium tuberculosis complex. J Clin Microbiol 34, 2843-2846.

Kamerbeek, J., Schouls, L., Kolk, A. \& 8 other authors (1997). Simultaneous detection and strain differentiation of Mycolsacterium tuberculosis for diagnosis and epidemiology. J Clin Microbiol 35, 907-914.

Kelman, Z. \& Moran, L. (1996). Degradation of ancient DNA. Curr Biol 6, 223.

Kent, L., McHugh, T. D., Billington, O., Dale, J. W. \& Gillespie, S. H. (1995). Demonstration of homology between IS6110 of
Mycobacterium tuberculosis and DNAs of other Mycobacterium spp. J Clin Microbiol 33, 2290-2293.

Legge, A. J. (1996). The beginning of caprine domestication in Southwest Asia. In The Origins and Spread of Agriculture and Pastoralism in Eurasia, pp. 238-262. Edited by D. R. Harris. London: UCL Press.

Liebana, E., Aranaz, A., Francis, B. \& Cousins, D. (1996). Assessment of genetic markers for species differentiation within the Mycobacterium tuberculosis complex. J Clin Microbiol 34, 933-938.

Nerlick, A. G., Haas, C. J., Zink, A., Sziemies, U. \& Hagedorn, H. G. (1997). Molecular evidence for tuberculosis in an ancient Egyptian mummy. Lancet 350, 1404.

O'Reilly, L. M. \& Daborn, C. J. (1995). The epidemiology of tuberculosis infections in animals and man: a review. Tubercle Lung Dis 76 suppl. 1, 1-46.

Rafi, A., Spigelman, M., Stanford, J., Lemma, E., Donoghue, H. \& Zias, J. (1994). DNA of Mycobacterium leprae detected by PCR in ancient bone. Int J Osteoarchaeol 4, 287-290.

Rodriguez, J. G., Mejia, G. A., Del Portillo, P., Patarroyo, M. E. \& Murillo, L. A. (1995). Species-specific identification of Mycobacterium bovis by PCR. Microbiology 141, 2131-2138.

Ryan, F. (1994). Tuberculosis, the Greatest Story Never Told. Worcestershire, UK: Swift Publishers.

Salo, W. L., Aufderheide, A. C., Buikstra, J. \& Holcomb, T. A. (1994). Identification of Mycobacterium tuberculosis DNA in a pre-Colombian Peruvian mummy. Proc Natl Acad Sci USA 91, 2091-2094.

Snider, D. E. \& La Montagne, J. R. (1994). The neglected global tuberculosis problem: a report of the 1992 World Congress on Tuberculosis. J Infect Dis 169, 1189-1196.

Sreevatsan, S., Escalante, P., Pan, X. \& 11 other authors (1996). Identification of a polymorphic nucleotide in $o x y R$ specific for Mycobacterium bovis. J Clin Microbiol 34, 2007-2010.

Sreevatsan, S., Pan, X., Stockbauer, K. E., Connell, N. D., Kreiswirth, B. N., Whittam, T. S. \& Musser, J. M. (1997). Restricted structural gene polymorphism in the Mycobacterium tuberculosis complex indicates evolutionarily recent global dissemination. Proc Natl Acad Sci USA 94, 9869-9874.

Taylor, G. M., Crossey, M., Saldanha, J. A. \& Waldron, T. (1996). Detection of Mycobacterium tuberculosis bacterial DNA in medieval human skeletal remains using polymerase chain reaction. J Archaeol Sci 23, 789-798.

Taylor, G. M., Rutland, P. \& Molleson, T. I. (1997). A sensitive PCR method for the diagnosis of Plasmodium species DNA in ancient human remains. Ancient Biomol 1, 193-203.

Telenti, A., Imboden, P., Marchesi, F., Lowrie, D., Cole, S., Colston, M. J., Matter, L., Schopfer, K. \& Bodmer, T. (1993). Detection of rifampicin-resistance mutations in Mycobacterium tuberculosis. Lancet 341, 647-650.

Thierry, D., Cave, M. D., Eisenach, K. D., Crawford, J. T., Bates, J., Gicquel, B. \& Guesdon, J. L. (1990). IS6110, an IS-like element of Mycobacterium tuberculosis complex. Nucleic Acids Res 18, 188. Weil, A., Pliyatis, B. B., Butler, W. R., Woodley, C. L. \& Shinnick, T. M. (1996). The mtp40 gene is not present in all strains of Mycobacterium tuberculosis. J Clin Microbiol 34, 2309-2311.

Received 19 October 1998; revised 11 January 1999; accepted 15 January 1999. 